\title{
Interaction between Vascular Endothelial Growth Factor-A (rs2010963) Gene Polymorphisms and Dietary Diversity Score on Cardiovascular Risk Factors in Patients with Metabolic Syndrome
}

\author{
Mahdieh Abbasalizad Farhangi ${ }^{\mathrm{a}} \quad$ Mahdi Vajdi $^{\mathrm{b}}$ Leila Nikniaz ${ }^{\mathrm{c}}$ Zeinab Nikniaz ${ }^{\mathrm{d}}$ \\ ${ }^{a}$ Nutrition Research Center, Tabriz University of Medical Sciences, Tabriz, Iran; b Student Research Committee, \\ Tabriz University of Medical Sciences, Tabriz, Iran; 'Tabriz Health Services Management Research Center, Health \\ Management and Safety Promotion Research Institute, Tabriz University of Medical Sciences, Tabriz, Iran; ' ${ }^{\mathrm{L}}$ Liver and \\ Gastrointestinal Diseases Research Center, Tabriz University of Medical Sciences, Tabriz, Iran
}

\section{Keywords \\ Dietary diversity score - Metabolic syndrome - VEGFA . MMP-3}

\begin{abstract}
Background: The vascular endothelial growth factor-A (VEGFA) family of cytokines regulates proliferation, angiogenesis, and migration of endothelial cells, increases vascular permeability, and controls thrombogenicity. Recent studies have suggested that the VEGFA gene plays an important role in the pathogenesis of metabolic syndrome and its related disorders. Dietary diversity score (DDS) has also been shown to have potential favorable effects against features of metabolic syndrome. This study examined the interactions between +405 VEGFA C/G (rs2010963) polymorphism and DDS on the metabolic and biochemical profile of metabolic syndrome. Therefore, in the current study, we aimed to evaluate the interaction between DDS and VEGFA rs2010963 gene polymorphisms in modification of metabolic risk factors including serum lipids, blood pressure, serum adiponectin, and matrix metalloproteinase (MMP)-3 concentrations in patients with metabolic syndrome. Methods and Materials: In the current cross-sectional study, 254 patients with meta-
\end{abstract}

\begin{tabular}{ll}
\hline KARGER & ( 2019 The Author(s) \\
& Published by S. Karger AG, Basel Oparger \\
E-Mail karger@karger.com & This article is licensed under the Creative Commons Attribution- \\
www.karger.com/lfg & $\begin{array}{l}\text { NonCommercial-NoDerivatives 4.0 International License (CC BY- } \\
\text { NC-ND) (http://www.karger.com/Services/OpenAccessLicense). } \\
\text { Usage and distribution for commercial purposes as well as any dis- } \\
\text { tribution of modified material requires written permission. }\end{array}$
\end{tabular}

bolic syndrome were recruited. Measurements of blood pressure, anthropometric parameters, and dietary intakes were performed and the DDS was calculated. Biochemical variables including serum adiponectin concentrations, lipid profile, serum glucose, and MMP-3 concentrations were measured by enzyme-linked immunosorbent assay method (ELISA) and enzymatic colorimetric methods. Determination of +405 C/G VEGFA gene polymorphisms was performed using the polymerase chain reaction-restriction fragment length polymorphism (PCR-RFLP) technique. Results: Patients in the lowest DDS quartile had higher insulin and homeostatic model assessment of insulin resistance (HOMAIR), while patients in the highest DDS quartile had higher quantitative insulin check index (QUICKI; $p<0.05$ ). Higher serum triglyceride and systolic blood pressure (SBP) values and lower serum adiponectin concentrations were also observed in lower DDS quartiles $(p<0.05)$. Patients with the CC genotype in the VEGFA rs2010963 polymorphism had significantly higher body mass index (BMI), fasting blood glucose, aspartate aminotransferase (AST), and alanine aminotransferase (ALT; $p<0.05$ ) compared to patients with the other 2 genotypes. In lower quartiles of DDS, $30 \%$ of patients with metabolic syndrome had the GG genotype, while 30.4 and $30.8 \%$ of patients with metabolic syndrome in higher DDS
Mahdieh Abbasalizad Farhangi

Nutrition Research Center

Tabriz University of Medical Sciences

Attar Neysahbouri Street, Nutrition Faculty, Tabriz 5165665931 (Iran)

E-Mail abbasalizad_m@yahoo.com 
quartiles had GC and CC genotypes, respectively $(p=0.04)$. Conclusion: Our study found lower insulin resistance, serum triglyceride, and SBP and higher adiponectin concentrations among patients with metabolic syndrome in highest quartiles of DDS. Moreover, patients with the CC genotype were more likely to have higher BMI, fasting blood glucose, AST, and ALT. This significant interaction gives a possible evidence of a VEGFA-DDS association that may be relevant to metabolic syndrome. Further studies are warranted to clarify the underlying mechanisms of these interactions.

(C) 2019 The Author(s)

Published by S. Karger AG, Basel

\section{Background}

Metabolic syndrome is a cluster of cardio-metabolic risk factors associated with several abnormalities including cardiovascular disease (CVD) [1,2], chronic kidney disease [3], non- alcoholic fatty liver disease [4], as well as depression and mood disorders [5]. It is associated with a 2 -fold increase in risk of CVD, CVD mortality, and stroke $[6,7]$. The prevalence of metabolic syndrome is increasing worldwide. The Third National Health and Nutrition Examination Survey (NHANES III) reported the prevalence of the metabolic syndrome to range from 20 to $24 \%$ among US adults [8]. The reports showed that in Iran, $33.7 \%$ of adults aged $>20$ years old were suffering from metabolic syndrome [9]. Other studies reported 55 and $30.1 \%$ for the prevalence of metabolic syndrome in Iranian adult women and men, respectively [10]. According to the NCEP ATP III definition, metabolic syndrome is the presence of 3 or more of the following five abnormalities: high-density lipoprotein cholesterol (HDL-C) $<50 \mathrm{mg} / \mathrm{dL}$ in women and $<40 \mathrm{mg} / \mathrm{dL}$ in men, triglyceride (TG) level $\geq 150 \mathrm{mg} / \mathrm{dL}$, systolic (SBP)/diastolic blood pressure $\geq 130 / 85 \mathrm{~mm} \mathrm{Hg}$, waist circumference $\geq 88 \mathrm{~cm}$ in women and $\geq 102 \mathrm{~cm}$ in men, and fasting blood glucose (FBG) level $\geq 110 \mathrm{mg} / \mathrm{dL}$ [11]. Treatment and prevention approaches for metabolic syndrome are multifactorial, including behavior modifications, physical activity interventions, drug therapy, and alterations in dietary habits [12]. Moreover, many reports revealed the helpful role of healthy food and diet choices in the prevention and treatment of metabolic syndrome [13].

The effect of single dietary components including dietary macronutrients or dietary patterns and nutrients on vascular function, inflammatory responses, and the prevalence of metabolic syndrome has been extensively studied $[14,15]$. However, it is more useful and also more informative to assess overall diet instead of single nutrients, since no individual dietary component could be considered wholly responsible for the association between diet and the metabolic syndrome. Rather, it is the overall quality of the diet that appears to offer protection against lifestyle-related diseases such as metabolic syndrome, and that overall diet reflects the real-world eating behaviors of the population rather than single nutrients $[16,17]$. Dietary diversity score (DDS) is an approach to evaluate if the overall diet correlates positively with nutritional adequacy [18]. Several previous studies have evaluated the relationship between DDS and cardiovascular risk factors and non-alcoholic fatty liver disease [19,20]. According to these past studies, a higher DDS is related to higher intakes of calcium, vitamin C, and fiber [21]. Miller et al. [22] revealed a significant relationship between a poorly diversified regime and hypertension. The relationship between DDS and features of metabolic syndrome has also been evaluated by Azadbakht et al. [23] in healthy individuals (aged 18+ years old). These authors reported an inverse relationship between components of metabolic syndrome and DDS. It is well understood that human nutrition is affected by human genetics; numerous single nucleotide polymorphisms (SNPs) have been found to be related with nutrition and these SNPs can influence an individual's susceptibility to disease and response to diet [24]. It has been found that the interaction between endothelial cells and adipocytes play an important role in the pathogenesis of obesity and subsequent metabolic disorders [25]. Interaction between adipocytes and endothelial cells commonly takes place through the vascular endothelial growth factors (VEGFs) and their receptors; therefore, the role of these factors in metabolic disorders has been a primary focus of scientific consideration in recent decades [26]. VEGF is encoded by the VEGFA gene, which is located on chromosome 6 (6p21 3 ) and comprises 8 exons [27]. Several SNPs in the VEGF gene, such as the $+405 C / G(r s 2010963)$ polymorphism in the $5^{\prime}$ untranslated region, have an important effect on the production of VEGF protein because the GG genotype is associated with higher VEGF protein production in healthy persons [28]. Moreover, VEGFA gene polymorphisms have been associated with the odds of metabolic syndrome and its components [29] and are also known to be associated with obesity $[30,31]$. VEGFA is a potent multifunctional cytokine reported to induce migration and proliferation of endothelial cells, enhance vascular permeability, and modulate thrombogenicity [32]. It is a mediator of vascular and extra-vascular remodeling and inflammation that enhances antigen sensi- 
tization $[33,34]$. Therefore, VEGFA is implicated in normal and pathologic vascular development and neovascularization with major pathogenic role in the development of various abnormalities including atherosclerosis, adipose tissue expansion, tumor growth, diabetic retinopathy, and nephropathy [30]. Increased serum concentrations of VEGFA have been reported in individuals with metabolic syndrome [35], and plasma VEGFA concentrations are significantly associated with the components of metabolic syndrome, including body mass index (BMI), waist circumference, blood pressure, and inflammation [36]. Moreover, insulin resistance and hyperglycemia are potent stimulators of VEGFA secretion. Targeting VEGFA and its inhibition and blockage have been suggested as novel therapeutic approaches to improve insulin resistance, type 2 diabetes, and metabolic syndrome [37]. On the other hand, VEGFA is a potent inducer of matrix metalloproteinase (MMP)-3 expression both in vivo and in vitro $[38,39]$. MMP-3 is a key mediator of inflammation and angiogenesis in metabolic syndrome and is considered a possible target for its treatment $[40,41]$.

There are limited studies evaluating VEGFA and diet interactions. In the study by Schüler et al. [42], common variants of VEGFA strongly affect the VEGF-dietary fat interactions. Furthermore, polymorphisms in rs2010963 are associated with insulin resistance [43], diabetic retinopathy [44], polycystic ovary syndrome [45], and coronary artery disease $[46,47]$. In the previous report, we reported an association between dietary inflammatory index and VEGFA polymorphisms, and metabolic parameters in patients with metabolic syndrome [48]. However, no study has assessed the association of VEGFA (rs2010963) and DDS in patients with metabolic syndrome. Therefore, the current study aimed to assess two hypotheses: first, to evaluate DDS and its association with metabolic and biochemical risk factors of metabolic syndrome, and second, to assess the diet-gene association between DDS and +405 C/G VEGFA genotype among patients with metabolic syndrome.

\section{Methods and Materials}

\section{Design and Participants}

The study population comprised 254 patients with metabolic syndrome referring to outpatient clinics at the Tabriz University of Medical Sciences. Metabolic syndrome was defined according to the National Cholesterol Education Program's Adult Treatment Panel III (NCEP-ATP III) criteria [9]. Participants were aged 25 years old and above and were living in Tabriz. Exclusion criteria were as follows: any history of cardiovascular and renal diseases, type 2 diabetes mellitus and cancer, pregnancy, and taking anti- hypertensive or anti-hyperlipidemia medications. The study protocol was approved by the Ethics Committee of Tabriz University of Medical Sciences (IR.TBZMED.REC.1398.460) and all of the participants completed a written informed consent form prior participation in the study.

\section{Anthropometric Assessments}

Anthropometric measurements were taken by trained technicians according to standard procedures. Weight was measured to the nearest $0.1 \mathrm{~kg}$ with a high-precision mechanical scale and height was recorded to the nearest $0.1 \mathrm{~cm}$ with a stadiometer. BMI was calculated as weight $(\mathrm{kg})$ divided by height squared $\left(\mathrm{m}^{2}\right)$. Waist circumference was measured $(\mathrm{cm})$ in horizontal plane, midway between the lowest rib and the iliac crest with a measuring tape. Waist-to-hip ratio was calculated as waist circumference divided by hip circumference.

\section{Biochemical Assays}

The assessment of FBG, aspartate aminotransferase (AST), alanine aminotransferase (ALT), TG, total cholesterol, HDL-C, and low-density lipoprotein cholesterol were analyzed by enzymatic colorimetric method (Pars - Azmoon, Tehran, Iran). Serum insulin was also analyzed using an enzyme-linked immunosorbent assay method (ELISA; Monobind Insulin AccuBind, Lake Forest, CA, USA); the sensitivity of this assay was $0.75 \mu \mathrm{IU} / \mathrm{mL}$ and mean inter- and intra-assay coefficients of variation were of $<9.8$ and $<8 \%$, respectively. Serum MMP-3 was also analyzed by ELISA method (AviBion, Vantaa, Finland), with a sensitivity of $0.01 \mathrm{ng} /$ $\mathrm{mL}$ and assay range of $0.05-10 \mathrm{ng} / \mathrm{mL}$. Serum adiponectin was also analyzed by ELISA (AviBion, Vantaa, Finland), with a sensitivity of $<0.185 \mathrm{ng} / \mathrm{mL}$ and mean inter- and intra-assay coefficients of variation of $\leq 12$ and $\leq 10 \%$, respectively. Insulin resistance was assessed using the homeostasis model assessment of insulin resistance (HOMA-IR) as follows: HOMA-IR: (glucose [mmol/L] $\times$ insulin $[\mathrm{mU} / \mathrm{L}]) / 405$, where a high HOMA-IR score denotes insulin resistance. The quantitative insulin check index (QUICKI) was calculated as: $1 /(\log$ fasting insulin $[\mathrm{U} / \mathrm{L}]+\log$ fasting glucose [mg/ $\mathrm{dL}]$ ), where a higher QUICKI value indicates greater insulin sensitivity $[49,50]$.

\section{Dietary Diversity Score (DDS)}

Dietary intake was assessed using a 147 -item semiquantitative standard food frequency questionnaire adopted and validated for use in the Iranian population [51]. The questionnaire consisted of a list of foods with standard serving sizes commonly used by Iranians. Participants reported frequency of consumption of a given food item during the previous year on a daily, weekly, or monthly manner. Then, food portion sizes were converted to grams. DDS was calculated by the method first developed by Kant et al. [18, 52]. Five food groups corresponding to bread and grains, vegetables, fruits, meats, and dairy were considered according to the food groups introduced by US Department of Agriculture (USDA) food guide pyramid. These food groups were divided into 23 groups. The bread-grain group was divided into 7 subgroups (refined bread, biscuits, macaroni, whole bread, corn flakes, rice, and refined flour), the vegetable group divided into 7 subgroups (vegetable, potato, tomato, other starchy vegetables, legumes, yellow vegetables, green vegetables), and fruits into 2 subgroups (fruits and fruit juices). Four subgroups were defined for the meat group (red meat, poultry, fish, and eggs) and 3 subgroups were considered for 
Table 1. Metabolic profile among study participants according to DDS quartiles

\begin{tabular}{|c|c|c|c|c|c|}
\hline & \multicolumn{4}{|c|}{ Quartiles of DDS } & \multirow[t]{2}{*}{$p$ value } \\
\hline & 1 st $(n=63)$ & $2 \mathrm{nd}(n=64)$ & $3 \mathrm{rd}(n=63)$ & 4 th $(n=64)$ & \\
\hline Age, years & $46 \pm 9$ & $42 \pm 8$ & $44 \pm 10$ & $43 \pm 11$ & 0.560 \\
\hline Male, \% & 69 & 56 & 63 & 70 & 0.742 \\
\hline BMI & $29 \pm 5$ & $28 \pm 4$ & $31 \pm 5$ & $33 \pm 4$ & 0.073 \\
\hline WHR & $0.95 \pm 0.11$ & $0.92 \pm 0.081$ & $0.91 \pm 0.047$ & $0.95 \pm 0.078$ & 0.211 \\
\hline ALT, IU/L & $18 \pm 10$ & $18 \pm 6$ & $21 \pm 11$ & $21 \pm 12$ & 0.684 \\
\hline AST, IU/L & $20 \pm 8$ & $19 \pm 7$ & $22 \pm 10$ & $24 \pm 13$ & 0.400 \\
\hline Adiponectin, ng/mL & $12 \pm 4^{\mathrm{a}}$ & $14 \pm 4$ & $14 \pm 4$ & $15 \pm 6$ & 0.011 \\
\hline $\mathrm{FBG}, \mathrm{mg} / \mathrm{dL}$ & $94 \pm 12$ & $88 \pm 12$ & $88 \pm 14$ & $90 \pm 16$ & 0.128 \\
\hline Insulin, $\mu \mathrm{IU} / \mathrm{L}$ & $28 \pm 10^{\mathrm{a}}$ & $9 \pm 1$ & $12 \pm 6$ & $19 \pm 6$ & 0.012 \\
\hline HOMA-IR & $6 \pm 2^{\mathrm{a}}$ & $2 \pm 1$ & $2 \pm 1$ & $4 \pm 5$ & 0.050 \\
\hline QUICKI & $0.32 \pm 0.05$ & $0.32 \pm 0.05$ & $0.35 \pm 0.03^{\mathrm{a}}$ & $0.33 \pm 0.05^{\mathrm{a}}$ & 0.049 \\
\hline $\mathrm{TG}, \mathrm{mg} / \mathrm{dL}$ & $200 \pm 105^{\mathrm{a}}$ & $198 \pm 141$ & $195 \pm 120$ & $168 \pm 71$ & 0.038 \\
\hline $\mathrm{TC}, \mathrm{mg} / \mathrm{dL}$ & $189 \pm 53$ & $192 \pm 38$ & $187 \pm 34$ & $191 \pm 38$ & 0.497 \\
\hline $\mathrm{LDL}, \mathrm{mg} / \mathrm{dL}$ & $122 \pm 5$ & $123 \pm 35$ & $123 \pm 46$ & $122 \pm 55$ & 0.277 \\
\hline $\mathrm{HDL}, \mathrm{mg} / \mathrm{dL}$ & $40 \pm 11$ & $41 \pm 9$ & $41 \pm 9$ & $42 \pm 11$ & 0.874 \\
\hline $\mathrm{SBP}, \mathrm{mm} \mathrm{Hg}$ & $133 \pm 10^{\mathrm{a}}$ & $132 \pm 9$ & $129 \pm 9$ & $129 \pm 3$ & 0.043 \\
\hline $\mathrm{DBP}, \mathrm{mm} \mathrm{Hg}$ & $88 \pm 5$ & $88 \pm 3$ & $89 \pm 7$ & $88 \pm 9$ & 0.609 \\
\hline MMP-3, ng/mL & $4 \pm 4$ & $3 \pm 2$ & $5 \pm 3$ & $5 \pm 3$ & 0.358 \\
\hline
\end{tabular}

Continuous variables are presented as mean \pm SD. The $p$ values for biochemical variables are obtained from ANCOVA adjusted for BMI, age, and gender, and for gender, it is obtained according to chi-square test. ${ }^{\text {a Sig- }}$ nificantly different compared with other quartiles according to post hoc analysis of Bonferroni correction tests. BMI, body mass index; WHR, waist-to-hip ratio; ALT, alanine aminotransferase; AST, aspartate aminotransferase; FBG, fasting blood glucose; HOMA-IR, homeostatic model assessment of insulin resistance; QUICKI, Quantitative Insulin Sensitivity Check Index; TG, triglyceride; TC, total cholesterol; LDL, low-density lipoprotein cholesterol; HDL, high-density lipoprotein cholesterol; SBP, systolic blood pressure; DBP, diastolic blood pressure; MMP-3, matrix metalloproteinase-3. The bold values present the statistically significant threshold.

the dairy group (milk, yogurt, and cheese). To be counted as consumer of one food group, participants had to consume at least one half serving per day, as defined by the food guide pyramid quantity criteria. A maximum score of 2 was considered for each food group. Therefore, the total DDS was in the range of 0 to 10 [23]. The DDS range in our participants was between 2.02 and 7.29. To examine the association between DDS and outcomes of interest, we divided the DDS into quartiles using the following cut-points: Q1: values $\leq 4.05$, Q2: values from 4.05 to 4.71 , Q3: values between 4.71 and 5.43 , and $\mathrm{Q} 4$ : values $\geq 5.43$.

Assessment of VEGF +405 C/G Polymorphism Genotype

Polymerase chain reaction-restriction fragment length polymorphism (PCR-RFLP) was employed to determine the VEGFA $+405 \mathrm{C} / \mathrm{G}$ polymorphism status with technical specifications. Primer pairs for $V E G F A+405 C / G$ polymorphism were as follows: forward: $5^{\prime}$-TTGCTTGCCATTCCC-CACTTGA-3' and backward: $5^{\prime}$-CCGAAGCGAGAACAGCCCAGAA- $3^{\prime}$. The PCR reaction was performed with $100 \mathrm{ng}$ genomic DNA, $25 \mu \mathrm{L}$ Taq PCR master mix RED (Ampliqon, Denmark), $2.5 \mu \mathrm{L}$ primers, and 12.5 $\mu \mathrm{L}$ deionized water under the following conditions of denaturation at $95^{\circ} \mathrm{C}$ for $5 \mathrm{~min}$ followed by 35 cycles at $94^{\circ} \mathrm{C}$ for $1 \mathrm{~min}, 60^{\circ} \mathrm{C}$ for $1.5 \mathrm{~min}$ (annealing), and $72^{\circ} \mathrm{C}$ for $2 \mathrm{~min}$ (extension). A final extension was at $72^{\circ} \mathrm{C}$ for $10 \mathrm{~min}$. For the VEGFA $405 \mathrm{C} / \mathrm{G}$ polymorphism, the PCR product was digested with the Bsm FI restric- tion nuclease (New England Biolabs, USA). All products were separated by electrophoresis using $1 \%$ agarose gel stained with ethidium bromide. For the VEGFA $+405 C / G$ polymorphism, the uncut fragment was $469 \mathrm{bp}$ (C allele) and digestion products were $195 \mathrm{bp}$ and $274 \mathrm{bp}$ (G allele). The additive model was used for SNP analyses, with 0 (GG), 1 (GC), or 2 (CC) alleles.

\section{Statistical Analysis}

Data were analyzed using Statistical Package for Social Science (SPSS) version 18. Data are presented as mean \pm SD or number and percentages. Comparison of variables between different DDS quartiles was performed by one-way ANCOVA by adjustment to confounder effects of BMI, age, and gender. The intra-group comparisons were followed by a post hoc Bonferroni correction. The comparison of qualitative variables across the quartiles of DDS was performed by $\chi^{2}$ test. $p$ values $<0.05$ were defined as the significance threshold. The interaction between $V E G F A+405 C / G$ polymorphism gene variant and DDS on metabolic parameters was evaluated using a general linear model, adjusting for the confounding effects of age, gender, and BMI. Considering an a error of 0.05 , effect size of 0.5 , and power of $80 \%$, the minimum sample required was determined as 211 individuals. Accordingly, allowing for $20 \%$ dropout, we enrolled 257 individuals; however, 3 individuals had incomplete data regarding questionnaires, blood samples, or genetic assays and were therefore removed from our analyses. There- 
Table 2. Metabolic profile among study populations according to VEGF rs2010963 polymorphisms

\begin{tabular}{|c|c|c|c|c|}
\hline & \multicolumn{3}{|c|}{ VEGF +405 G/C gene polymorphisms } & \multirow[t]{2}{*}{$p$ value } \\
\hline & $\mathrm{GG}(n=74)$ & $\mathrm{GC}(n=132)$ & $\mathrm{CC}(n=48)$ & \\
\hline Age, years & $44 \pm 10$ & $43 \pm 10$ & $44 \pm 9$ & 0.615 \\
\hline Male, \% & 64 & 65 & 64 & 0.911 \\
\hline BMI & $31 \pm 6$ & $30 \pm 5$ & $32 \pm 6$ & 0.027 \\
\hline WHR & $0.93 \pm 0.07$ & $0.93 \pm 0.07$ & $0.93 \pm 0.06$ & 0.960 \\
\hline ALT, IU/L & $20 \pm 11$ & $24 \pm 11$ & $27 \pm 12^{\mathrm{a}}$ & 0.049 \\
\hline AST, IU/L & $20 \pm 7$ & $23 \pm 7$ & $26 \pm 10^{\mathrm{a}}$ & 0.037 \\
\hline Adiponectin, ng/mL & $12 \pm 5$ & $15 \pm 5$ & $13 \pm 4$ & 0.240 \\
\hline $\mathrm{FBG}, \mathrm{mg} / \mathrm{dL}$ & $89 \pm 9$ & $88 \pm 11$ & $92 \pm 19^{a}$ & 0.047 \\
\hline Insulin, $\mu \mathrm{IU} / \mathrm{L}$ & $15 \pm 10$ & $18 \pm 10$ & $13 \pm 3$ & 0.871 \\
\hline HOMA-IR & $3 \pm 1$ & $4 \pm 1$ & $3 \pm 1$ & 0.888 \\
\hline QUICKI & $0.34 \pm 0.05$ & $0.33 \pm 0.04$ & $0.33 \pm 0.01$ & 0.591 \\
\hline $\mathrm{TG}, \mathrm{mg} / \mathrm{dL}$ & $187 \pm 74$ & $163 \pm 90$ & $182 \pm 73$ & 0.405 \\
\hline $\mathrm{TC}, \mathrm{mg} / \mathrm{dL}$ & $191 \pm 39$ & $194 \pm 41$ & $189 \pm 31$ & 0.850 \\
\hline $\mathrm{LDL}, \mathrm{mg} / \mathrm{dL}$ & $122 \pm 32$ & $127 \pm 32$ & $120 \pm 30$ & 0.549 \\
\hline $\mathrm{HDL}, \mathrm{mg} / \mathrm{dL}$ & $43 \pm 13$ & $45 \pm 11$ & $45 \pm 10$ & 0.740 \\
\hline $\mathrm{SBP}, \mathrm{mm} \mathrm{Hg}$ & $128 \pm 12$ & $133 \pm 11$ & $132 \pm 12$ & 0.333 \\
\hline $\mathrm{DBP}, \mathrm{mm} \mathrm{Hg}$ & $87 \pm 6$ & $89 \pm 6$ & $90 \pm 7$ & 0.371 \\
\hline MMP-3, ng/mL & $3 \pm 1$ & $4 \pm 1$ & $5 \pm 1$ & 0.599 \\
\hline
\end{tabular}

Continuous variables are presented as mean \pm SD. The $p$ values for biochemical variables are obtained from ANCOVA adjusted for BMI, age, and gender, and for gender, it is obtained according to chi-square test. ${ }^{\text {a Sig- }}$ nificantly different compared with other quartiles according to post hoc analysis of Bonferroni correction tests. BMI, body mass index; WHR, waist-to-hip ratio; ALT, alanine aminotransferase; AST, aspartate aminotransferase; FBG, fasting blood glucose; HOMA-IR, homeostatic model assessment of insulin resistance; QUICKI, Quantitative Insulin Sensitivity Check Index; TG, triglyceride; TC, total cholesterol; LDL, low-density lipoprotein cholesterol; HDL, high-density lipoprotein cholesterol; SBP, systolic blood pressure; DBP, diastolic blood pressure; MMP-3, matrix metalloproteinase-3. The bold values present the statistically significant threshold.

fore, the final sample size was 254 individuals. The total sample size could detect an intra-class correlation $(\rho)$ equal to $0.25-0.36$ as the effective sample size for the association between DDS and metabolic syndrome [53], based on the $G$ * Power version 3.1.7 (Franz Faul, University of Kiel, Kiel, Germany).

\section{Results}

The comparison of biochemical variables in different DDS quartiles are presented in Table 1. Patients in the lowest DDS quartile had higher insulin and HOMA-IR compared with other quartiles, while patients in the highest DDS quartile had a higher QUICKI index. Although there was a significant difference between the lowest and highest DDS quartiles for insulin, there was an irregular change in the trend of this parameter across quartiles. The lower quartile also showed higher serum TG and SBP values and lower serum adiponectin concentrations compared with the higher DDS category $(p<0.05)$.

VEGFA rs2010963 Gene Polymorphisms and DDS Interaction
Table 2 presents the metabolic profile in different $V E G F A+405 C / G$ genotypes. Higher BMI, FBG, AST, and ALT concentrations were observed in different VEG$F A+405 C / G$ genotypes. The $C C$ genotype had higher BMI $(32 \pm 6 ; p=0.027)$, FBG $(92 \pm 19 \mathrm{mg} / \mathrm{dL} ; p=0.047)$, AST $(26 \pm 10 \mathrm{IU} / \mathrm{L} ; p=0.037)$, and ALT $(27 \pm 12 \mathrm{IU} / \mathrm{L}$; $p=0.049)$ compared to the other 2 genotypes. No significant difference was observed between other biochemical parameters. The comparison of total and food group DDS in different genotypes of VEGFA rs 2010963 polymorphisms is presented in Table 3. In the lower quartiles of DDS, $30 \%$ of patients with metabolic syndrome had the GG genotype, while 30.4 and $30.8 \%$ of patients with metabolic syndrome in the higher DDS quartiles had GC and CC genotypes, respectively ( $p=0.041)$. No difference in DDS of food groups among different VEGFA +405 $C / G$ genotypes was observed.

Figure 1 presents the interaction between DDS and $V E G F A+405 C / G$ genotypes for various biochemical variables. The general linear model showed that the DDS- 
Table 3. The comparison of total DDS and food group DDS according to VEGF +405 G/C genotype

\begin{tabular}{lllll}
\hline \multicolumn{4}{l}{} & \multicolumn{3}{l}{ VEGF +405 G/C gene polymorphisms } & \\
\cline { 2 - 5 } & $\begin{array}{l}\text { GG } \\
(n=74)\end{array}$ & $\begin{array}{l}\text { GC } \\
(n=132)\end{array}$ & $\begin{array}{l}\text { CC } \\
(n=48)\end{array}$ & $p$ value \\
\hline DDS quartiles, \% & & & & $0.041^{*}$ \\
$\quad$ 1st & 30 & 17.4 & 16.4 & \\
$\quad$ 2nd & 30 & 17.4 & 16.4 & \\
$\quad$ 3rd & 20 & 34.8 & 36.4 & \\
$\quad$ 4th & 20 & 30.4 & 30.8 & \\
Grain DS & $0.76 \pm 0.20$ & $0.80 \pm 0.53$ & $0.83 \pm 0.14$ & 0.632 \\
Fruit DS & $1.13 \pm 0.62$ & $1.28 \pm 0.53$ & $1.07 \pm 0.49$ & 0.376 \\
Vegetable DS & $0.71 \pm 0.4$ & $0.79 \pm 0.39$ & $0.82 \pm 0.23$ & 0.634 \\
Dairy DS & $1.47 \pm 0.57$ & $1.62 \pm 0.42$ & $1.69 \pm 0.44$ & 0.395 \\
Meat DS & $0.54 \pm 0.12$ & $0.54 \pm 0.08$ & $0.50 \pm 0.12$ & 0.976 \\
ED & $0.88 \pm 0.14$ & $0.91 \pm 0.27$ & $0.92 \pm 0.22$ & 0.872 \\
\hline
\end{tabular}

* Statistically significant $p$ values are obtained from chi-square test. The continuous variables are compared according to ANOVA. DDS, dietary diversity score; DS, diversity score; VEGF, vascular endothelial growth factor; ED, energy density.

gene interaction significantly affected SBP, AST, and MMP-3 in participants ( $p_{\text {interaction }}=0.003,0.02$, and 0.049 , respectively). As shown in this figure, the highest DDS quartiles showed a significant association with reduced AST concentrations in individuals with the CC and GG genotypes $\left(p_{\text {interaction }}=0.02\right)$. SBP values were increased in individuals with the CC genotype in higher versus lower DDS quartiles, while MMP-3 values were increased in all 3 genotypes (GG, CC, and GC) in higher versus lower DDS quartiles ( $\left.p_{\text {interaction }}=0.049\right)$. In terms of MMP-3, it also appeared that having the G allele in VEGFA+ 405 $C / G$ alleviated the effects of DDS on MMP-3.

\section{Discussion}

The current study was conducted in patients with metabolic syndrome and showed that patients with lower DDS scores had significantly higher serum TG and insulin concentrations, lower SBP and HOMA-IR values, and lower adiponectin concentrations compared with patients with higher DDS scores. Moreover, most of the patients with metabolic syndrome in the highest DDS quartiles carried the GC and CC genotypes. According to our findings, the $V E G F A+405 C / G$ polymorphism significantly affected biochemical parameters. In terms of MMP-3, our data suggests that having the G allele in VEGFA+ $405 \mathrm{C} / \mathrm{G}$ may alleviate the effects of DDS on MMP-3.
The current study was the first one to evaluate the interaction between the VEGFA $+405 C / G$ genotype and DDS on the metabolic profile of patients with metabolic syndrome. To the best of our knowledge, only one study [53] previously evaluated the relationship between DDS and metabolic syndrome components in a healthy Iranian population, but not in patients with metabolic syndrome. The findings of the current study revealed that higher DDS scores were associated with lower serum TG, insulin, HOMA-IR, and SBP values as well as higher serum adiponectin concentrations. Previous studies also revealed a lower probability of hypertension, hypercholesterolemia, and diabetes in individuals with a higher DDS in a population-based study [23]. An inverse association between age-adjusted risk of mortality and DDS in men and women has also been observed [18]. It is proposed that increasing the whole dietary diversity, which includes sugar and fat, may be related with an elevated risk of obesity and its related disorders, while increasing the diversity score of vegetable and fruit may be related with a reduction in metabolic disease. Kant et al. [52] showed no significant relationship between diet diversity and BMI [54]. Numerous studies previously reported the favorable effects of a high DDS against chronic disease, including lower depression rates among women [55], lower prevalence of anxiety [56], and lower risk of colorectal [57] and breast cancer [58]. Diets with higher diversity are associated with increased intakes of essential micronutrients including vitamin $\mathrm{C}$, calcium, and dietary fiber $[59,60]$. Our study found higher serum adiponectin concentrations in individuals in the higher DDS categories. Previous studies have established a positive association between healthy dietary parameters and serum adiponectin concentrations [61, 62]. Positive associations between higher serum adiponectin concentrations and increased dietary intakes of vegetable, vegetable oil, coffee [63], and green tea consumption [64] have been previously noted, while a negative association was found with increased consumption of mixed bread, fried and baked dishes, alcohol, nuts, and seeds. Adiponectin is a wellknown anti-diabetic, anti-sclerotic, and anti-hypertensive hormone [65]. Unlike other adipose tissue-derived cytokines, adiponectin is reduced in diabetes, insulin resistance, and cardiovascular events. A healthy diet including higher DDS as found in our study increases its concentration and reduces the risk of type 2 diabetes, insulin resistance, and atherosclerosis [61-64].

In a previous study by Kim and Hong [65], the CC genotype of the VEGFA polymorphism was related to significantly increased BMI, FBS, TG, and HDL-C in a Ko-
$6 \quad$ Lifestyle Genomics 2020;13:1-10 DOI: $10.1159 / 000503789$
Abbasalizad Farhangi/Vajdi/Nikniaz/ Nikniaz 


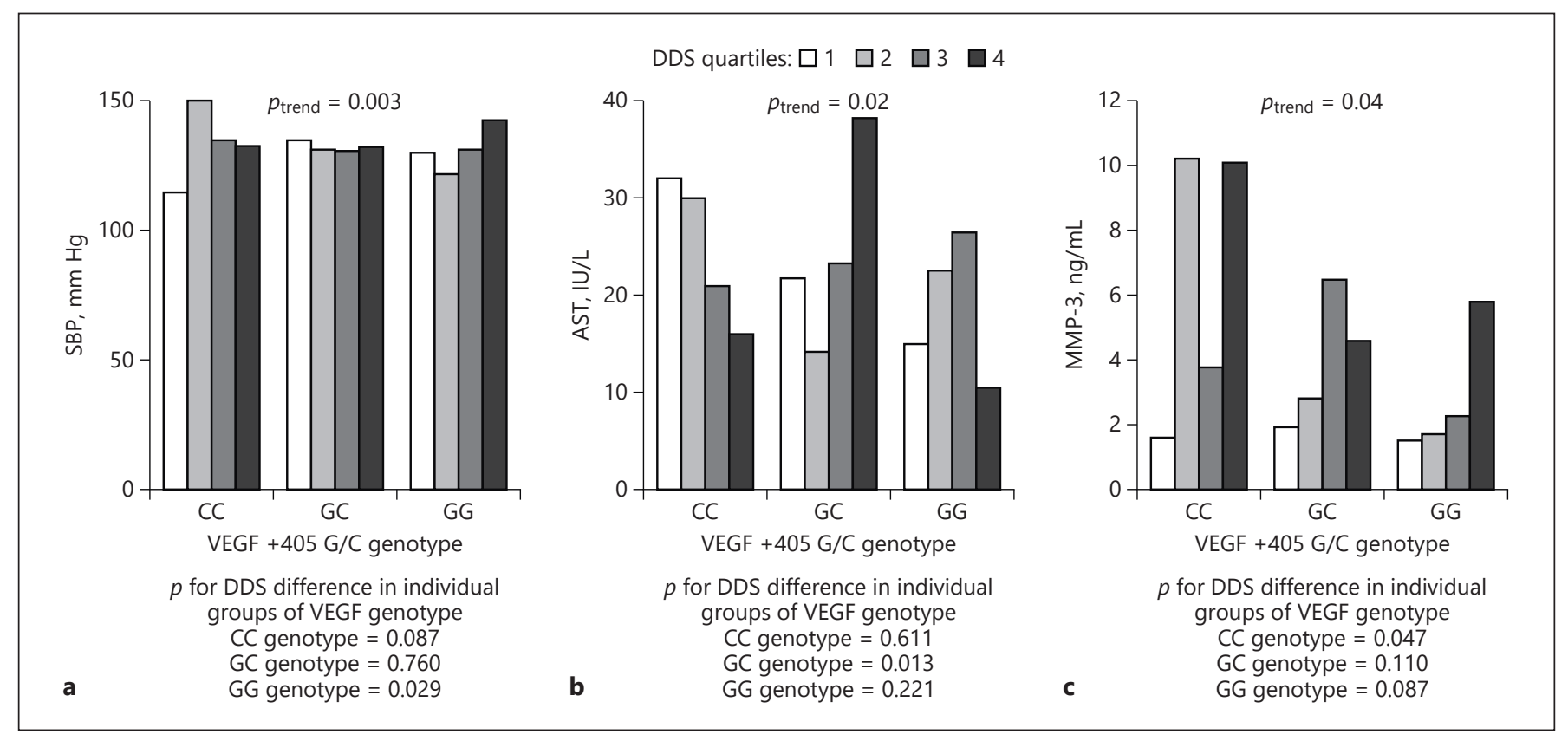

Fig. 1. Significant interactions between $V E G F+405 G / C$ polymorphisms and DDS quartiles affecting SBP (a), AST (b), and MMP-3 (c). pinteraction was determined by general linear model with the covariates of age and gender. The intra-group comparisons of parameters are provided by ANCOVA after adjusting for the covariates of age and gender.

rean population. Also, Nikzamir et al. [66] reported that the GG genotype in the $+405 \mathrm{C} / \mathrm{G}$ polymorphism is independently related with the development of diabetic nephropathy. According to our results, carriers of the CC genotype had the highest values of FBG, AST, and ALT. Previous studies have shown that carriers of the $\mathrm{C}$ allele of VEGFA rs2010963 are more prone to having higher serum VEGFA concentrations [67]. Moreover, the C allele of VEGFA $+405 \mathrm{C} / \mathrm{G}$ polymorphism was also associated with a higher rate of metabolic disorders, including diabetic retinopathy [44]. Higher serum concentrations of VEGFA are associated with metabolic syndrome [35] and higher BMI, blood pressure, and inflammation [36]. Therefore, it could be assumed that targeting VEGFA and reducing its expression could be a novel therapeutic approach to decrease the risk of insulin resistance, type 2 diabetes, and metabolic syndrome [37]. As shown in our results, the DDS significantly interacted with the VEGF $+405 \mathrm{C} / \mathrm{G}$ genotype to influence several biochemical variables, including AST, ALT, and SBP. In people with the CC genotype, which is a possible risk factor of metabolic syndrome, reduced AST and increased SBP values were observed in those with the highest versus lowest DDS. Meanwhile, individuals with the GC genotype showed higher AST and MMP-3 and reduced SBP values in high-

VEGFA rs2010963 Gene Polymorphisms and DDS Interaction est versus lowest DDS quartiles. The GG genotype increased MMP-3 and SBP and reduced AST in those with the highest versus lowest DDS. This significant interaction provides possible evidence of a DDS-VEGF association; however, further studies are warranted to better elucidate the clinical implications of the current study.

Mean DDS score of our study among patients with metabolic syndrome was $5 \pm 1$. This value was lower than the corresponding values of $6 \pm 1$ among an apparently healthy population in Iran [53] or $6 \pm 2$ among collegeemployed men and women in Iran [68], revealing the lower DDS scores among patients with metabolic syndrome. However, considering the lack of knowledge about the relationship between DDS and VEGFA gene polymorphism in patients with metabolic syndrome, further intervention studies are needed to evaluate DDS in patients with metabolic syndrome disease according to the various genotypes of the VEGFA $+405 C / G$ polymorphisms.

\section{Conclusion}

Our study found lower insulin resistance, serum TG, and SBP and higher adiponectin concentrations in individuals in the highest quartiles of DDS among patients 
with metabolic syndrome. Moreover, patients with the CC genotype in the VEGFA $+405 C / G$ variant were more likely to have higher BMI, FBG, AST, and ALT compared to patients with the other 2 genotypes. This significant interaction provides possible evidence of a DDS-VEGF association and its effects on the biochemical profile associated with metabolic syndrome. Further studies are warranted to clarify the underlying mechanisms of these interactions.

\section{Acknowledgement}

The authors appreciate the cooperation of patients in the current study.

\section{Statement of Ethics}

Participants in the study provided consent for participation. This work was supported by Nutrition Research Center, Tabriz University of Medical Sciences (IR.TBZMED.REC.1398.460). The study has been approved by the Ethics Committee of Tabriz University of Medical Sciences. We thank all of the study participants in the current research.

\section{Disclosure Statement}

The authors declare that there is no conflict of interest.

\section{Funding Sources}

This has been granted by Research Undersecretary of Tabriz University of Medical sciences (IR.TBZMED.REC.1398.460).

\section{Author Contributions}

M.A.F. was involved in designing of the project and wrote and revised the article draft and analyzed the data. L.N. was also involved in data collection, and Z.N. was involved in designing and patients' recruitment. M.V. was involved in revision and data analysis.

\section{References}

1 Reaven GM. Banting lecture 1988. Role of insulin resistance in human disease. Diabetes. 1988 Dec;37(12):1595-607.

2 Isomaa B, Almgren P, Tuomi T, Forsén B, Lahti $K$, Nissén $M$, et al. Cardiovascular morbidity and mortality associated with the metabolic syndrome. Diabetes Care. 2001 Apr;24(4):683-9.

3 Ritz E. Metabolic syndrome and kidney disease. Blood Purif. 2008;26(1):59-62.

4 Marchesini G, Brizi M, Bianchi G, Tomassetti $S$, Bugianesi E, Lenzi M, et al. Nonalcoholic fatty liver disease: a feature of the metabolic syndrome. Diabetes. 2001 Aug;50(8):1844-50.

5 Heiskanen TH, Niskanen LK, Hintikka JJ, Koivumaa-Honkanen HT, Honkalampi KM, Haatainen KM, et al. Metabolic syndrome and depression: a cross-sectional analysis. J Clin Psychiatry. 2006 Sep;67(9):1422-7.

6 Mottillo S, Filion KB, Genest J, Joseph L, Pilote L, Poirier P, et al. The metabolic syndrome and cardiovascular risk a systematic review and meta-analysis. J Am Coll Cardiol. 2010 Sep;56(14):1113-32.

7 Heshmat R, Shafiee G, Qorbani M, Azizi-Soleiman F, Djalalinia S, Esmaeil Motlagh M, et al. Association of ghrelin with cardiometabolic risk factors in Iranian adolescents: the CASPIAN-III study. J Cardiovasc Thorac Res. 2016;8(3):107-12.

8 Ford ES, Giles WH, Dietz WH. Prevalence of the metabolic syndrome among US adults: findings from the third National Health and Nutrition Examination Survey. JAMA. 2002 Jan;287(3):356-9.
9 Zabetian A, Hadaegh F, Azizi F. Prevalence of metabolic syndrome in Iranian adult population, concordance between the IDF with the ATPIII and the WHO definitions. Diabetes Res Clin Pract. 2007 Aug;77(2):251-7.

10 Azimi-Nezhad M, Herbeth B, Siest G, Dadé S, Ndiaye NC, Esmaily H, et al. High prevalence of metabolic syndrome in Iran in comparison with France: what are the components that explain this? Metab Syndr Relat Disord. 2012 Jun;10(3):181-8

11 Expert Panel on Detection, Evaluation, and Treatment of High Blood Cholesterol in Adults. Executive summary of the Third Report of the National Cholesterol Education Program (NCEP) expert panel on detection, evaluation, and treatment of high blood cholesterol in adults(Adult Treatment Panel III). JAMA. 2001 May;285(19):2486-97.

12 Aggarwal A, Aggarwal S, Sarkar PG, Sharma V. Predisposing factors to premature coronary artery disease in young (age $\leq 45$ years) smokers: a single center retrospective case control study from India. J Cardiovasc Thorac Res. 2014;6(1):15-9.

13 Farhangi MA, Jahangiry L, Mirinazhad MM, Shojaeezade D, Montazeri A, Yaghoubi A. A web-based interactive lifestyle modification program improves lipid profile and serum adiponectin concentrations in patients with metabolic syndrome: the "Red Ruby" study. Int J Diab Dev C. 2017;37(1):21-30.

14 McKeown NM, Meigs JB, Liu S, Saltzman E, Wilson PW, Jacques PF. Carbohydrate nutri- tion, insulin resistance, and the prevalence of the metabolic syndrome in the Framingham Offspring Cohort. Diabetes Care. 2004 Feb; 27(2):538-46.

15 Esposito K, Marfella R, Ciotola M, Di Palo C, Giugliano F, Giugliano G, et al. Effect of a mediterranean-style diet on endothelial dysfunction and markers of vascular inflammation in the metabolic syndrome: a randomized trial. JAMA. 2004 Sep;292(12):1440-6.

16 Baxter AJ, Coyne T, McClintock C. Dietary patterns and metabolic syndrome-a review of epidemiologic evidence. Asia Pac J Clin Nutr. 2006;15(2):134-42.

17 Hu FB. Dietary pattern analysis: a new direction in nutritional epidemiology. Curr Opin Lipidol. 2002 Feb;13(1):3-9.

18 Kant AK, Schatzkin A, Harris TB, Ziegler RG Block G. Dietary diversity and subsequent mortality in the First National Health and Nutrition Examination Survey Epidemiologic Follow-up Study. Am J Clin Nutr. 1993 Mar; 57(3):434-40.

19 Toft U, Kristoffersen LH, Lau C, Borch-Johnsen K, Jørgensen T. The Dietary Quality Score: validation and association with cardiovascular risk factors: the Inter99 study. Eur J Clin Nutr. 2007 Feb;61(2):270-8.

20 Hashemi Kani A, Alavian SM, Esmaillzadeh A, Adibi P, Azadbakht L. Dietary quality indices and biochemical parameters among patients with non alcoholic fatty liver disease (NAFLD). Hepat Mon. 2013 Jul; 13(7):e10943. 
21 Hatløy A, Torheim LE, Oshaug A. Food variety-a good indicator of nutritional adequacy of the diet? A case study from an urban area in Mali, West Africa. Eur J Clin Nutr. 1998 Dec;52(12):891-8.

22 Miller WL, Crabtree BF, Evans DK. Exploratory study of the relationship between hypertension and diet diversity among Saba Islanders. Public Health Rep. 1992 Jul-Aug;107(4) $426-32$.

23 Azadbakht L, Mirmiran P, Esmaillzadeh A, Azizi F. Dietary diversity score and cardiovascular risk factors in Tehranian adults. Public Health Nutr. 2006 Sep;9(6):728-36.

24 Williams CM, Ordovas JM, Lairon D, Hesketh J, Lietz G, Gibney M, et al. The challenges for molecular nutrition research 1: linking genotype to healthy nutrition. Genes Nutr. 2008 Jul;3(2):41-9.

25 Muniyappa R, Iantorno M, Quon MJ. An integrated view of insulin resistance and endothelial dysfunction. Endocrinol Metab Clin North Am. 2008;37:685-711.

26 Holmes DI, Zachary I. The vascular endothelial growth factor (VEGF) family: angiogenic factors in health and disease. Genome Biol. 2005;6(2):209.

27 Vincenti V, Cassano C, Rocchi M, Persico G. Assignment of the vascular endothelial growth factor gene to human chromosome 6p21.3. Circulation. 1996 Apr;93(8):1493-5.

28 Aiello LP, Avery RL, Arrigg PG, Keyt BA Jampel HD, Shah ST, et al. Vascular endothelial growth factor in ocular fluid of patients with diabetic retinopathy and other retinal disorders. N Engl J Med. 1994 Dec;331(22): $1480-7$

29 Zafar MI, Mills K, Ye X, Blakely B, Min J, Kong W, et al. Association between the expression of vascular endothelial growth factors and metabolic syndrome or its components: a systematic review and meta-analysis. Diabetol Metab Syndr. 2018 Aug;10(1):6279.

30 García de la Torre N, Rubio MA, Bordiú E, Cabrerizo L, Aparicio E, Hernández C, et al. Effects of weight loss after bariatric surgery for morbid obesity on vascular endothelial growth factor-A, adipocytokines, and insulin. J Clin Endocrinol Metab. 2008 Nov;93(11): 4276-81.

31 Loebig M, Klement J, Schmoller A, Betz S, Heuck N, Schweiger U, et al. Evidence for a relationship between VEGF and BMI independent of insulin sensitivity by glucose clamp procedure in a homogenous group healthy young men. PLoS One. 2010 Sep; 5(9):e12610.

32 Miyazawa-Hoshimoto S, Takahashi K, Bujo $\mathrm{H}$, Hashimoto N, Saito Y. Elevated serum vascular endothelial growth factor is associated with visceral fat accumulation in human obese subjects. Diabetologia. 2003 Nov; 46(11):1483-8

33 Lee CG, Link H, Baluk P, Homer RJ, Chapoval $S$, Bhandari $\mathrm{V}$, et al. Vascular endothelial growth factor (VEGF) induces remodeling and enhances $\mathrm{TH} 2$-mediated sensitization and inflammation in the lung. Nat Med. 2004 Oct;10(10):1095-103.

34 Khaki Khatibi F, Yaghoubi A, Zarghami N, Rahbani M, Babaie H. Evaluation of hs-CRP, antioxidant markers and MDA in patients of coronary artery disease (CAD) containing non-smokers and non-diabetics. J Cardiovasc Thorac Res. 2011;2(4):13-8.

35 Barylski M, Kowalczyk E, Banach M, Ciecwierz J, Pawlicki L, Kowalski J. Plasma total antioxidant activity in comparison with plasma NO and VEGF levels in patients with metabolic syndrome. Angiology. 2009 Feb-Mar; 60(1):87-92.

36 Siervo M, Ruggiero D, Sorice R, Nutile T, Aversano M, Iafusco M, et al. Body mass index is directly associated with biomarkers of angiogenesis and inflammation in children and adolescents. Nutrition. 2012 Mar;28(3): 262-6.

37 Wu LE, Meoli CC, Mangiafico SP, Fazakerley DJ, Cogger VC, Mohamad M, et al. Systemic vascular endothelial growth factor-A (VEGFA) neutralization ameliorates diet induced metabolic dysfunction. Diabetes. 2014;63(8): 2656-67.

38 Mo HY, Zhou RH, Wang XT, Yang M. Effect of vascular endothelial growth factor on the expression of matrix metalloproteinase- 3 and matrix metalloproteinase- 9 synoviocytes in adjuvant arthritis. CRTER. 2007;11(27): 5307-10.

39 Pufe T, Harde V, Petersen W, Goldring MB, Tillmann B, Mentlein R. Vascular endothelial growth factor (VEGF) induces matrix metalloproteinase expression in immortalized chondrocytes. J Pathol. 2004 Mar;202(3): 367-74.

40 Hopps E, Caimi G. Matrix metalloproteinases in metabolic syndrome. Eur J Intern Med. 2012 Mar;23(2):99-104.

41 Berg GA, Miksztowicz VJ. Metalloproteinases in the pathogenesis and progression of metabolic syndrome: potential targets for improved outcomes. J Metalloproteinases Med. 2015;2:51-9.

42 Schüler R, Seebeck N, Osterhoff MA, Witte V, Flöel A, Busjahn A, et al. VEGF and GLUT1 are highly heritable, inversely correlated and affected by dietary fat intake: consequences for cognitive function in humans. Mol Metab. 2018 May;11:129-36.

43 Vural P, Küskü-Kiraz Z, Doğru-Abbasoğlu S, Cil E, Karadağ B, Uysal M. Vascular endothelial growth factor $+405 \mathrm{G} / \mathrm{C},-460 \mathrm{~T} / \mathrm{C}$ and $-2578 \mathrm{~A} / \mathrm{C}$ polymorphisms are not associated with insulin resistance in polycystic ovary syndrome. Int J Immunogenet. 2010 Aug; 37(4):239-43.

44 Badr Mohammed S, Al-awadi S, Algenabi A. Vascular Endothelial Growth Factor +405 G/C Polymorphism and Diabetic Retinopathy. Int J Adv Res (Indore). 2013;1(8):278-86.

45 Ben Salem A, Megdich F, Kacem O, Souayeh M, Hachani Ben Ali F, Hizem S, et al. Vascular endothelial growth factor (VEGFA) gene variation in polycystic ovary syndrome in a Tunisian women population. BMC Genomics. 2016 Oct;17(S9 Suppl 9):748-55.

46 Moradzadegan A, Vaisi-Raygani A, Nikzamir A, Rahimi Z. Angiotensin converting enzyme insertion/deletion (I/D) (rs4646994) and Vegf polymorphism (+405G/C; rs2010963) in type II diabetic patients: association with the risk of coronary artery disease. J Renin Angiotensin Aldosterone Syst. 2015 Sep;16(3):67280.

47 van der Meer P, De Boer RA, White HL, van der Steege G, Hall AS, Voors AA, et al. The VEGF +405 CC promoter polymorphism is associated with an impaired prognosis in patients with chronic heart failure: a MERIT-HF substudy. J Card Fail. 2005 May;11(4):279_ 84.

48 Abbasalizad Farhangi M, Vajdi M, Nikniaz L Nikniaz Z. The interaction between dietary inflammatory index and 6 P21 rs2010963 gene variants in metabolic syndrome. Eat Weight Disord. 2019, Epub ahead of print.

49 Matthews DR, Hosker JP, Rudenski AS, Naylor BA, Treacher DF, Turner RC. Homeostasis model assessment: insulin resistance and beta-cell function from fasting plasma glucose and insulin concentrations in man. Diabetologia. $1985 \mathrm{Jul} ; 28(7): 412-9$.

50 Viner RM, Segal TY, Lichtarowicz-Krynska E, Hindmarsh P. Prevalence of the insulin resistance syndrome in obesity. Arch Dis Child. 2005 Jan;90(1):10-4.

51 Esfahani FH, Asghari G, Mirmiran P, Azizi F. Reproducibility and relative validity of food group intake in a food frequency questionnaire developed for the Tehran Lipid and Glucose Study. J Epidemiol. 2010;20(2):150-8.

52 Kant AK, Block G, Schatzkin A, Ziegler RG, Nestle M. Dietary diversity in the US population, NHANES II, 1976-1980. J Am Diet Assoc. 1991 Dec;91(12):1526-31.

53 Azadbakht L, Mirmiran P, Azizi F. Dietary diversity score is favorably associated with the metabolic syndrome in Tehranian adults. Int J Obes. 2005 Nov;29(11):1361-7.

54 Heidemann C, Hoffmann K, Spranger J, Klipstein-Grobusch K, Möhlig M, Pfeiffer $\mathrm{AF}$, et al.; European Prospective Investigation into Cancer and Nutrition (EPIC)Potsdam Study Cohort. A dietary pattern protective against type 2 diabetes in the $\mathrm{Eu}$ ropean Prospective Investigation into Cancer and Nutrition (EPIC) - potsdam Study cohort. Diabetologia. 2005 Jun;48(6):112634.

55 Poorrezaeian M, Siassi F, Milajerdi A, Qorbani M, Karimi J, Sohrabi-Kabi R, et al. Depression is related to dietary diversity score in women: a cross-sectional study from a developing country. Ann Gen Psychiatry. 2017 Nov;16(1):39-48.

56 Poorrezaeian M, Siassi F, Qorbani M, Karimi J, Koohdani F, Asayesh H, et al. Association of dietary diversity score with anxiety in women. Psychiatry Res. 2015 Dec;230(2): 622-7. 
57 Fernandez E, Negri E, La Vecchia C, Franceschi S. Diet diversity and colorectal cancer. Prev Med. 2000 Jul;31(1):11-4.

58 Franceschi S, Favero A, La Vecchia C, Negri E, Dal Maso L, Salvini S, et al. Influence of food groups and food diversity on breast cancer risk in Italy. Int J Cancer. 1995 Dec;63(6): 785-9.

59 Mirmiran P, Azadbakht L, Esmaillzadeh A, Azizi F. Dietary diversity score in adolescents - a good indicator of the nutritional adequacy of diets: tehran lipid and glucose study. Asia Pac J Clin Nutr. 2004;13(1):56-60.

60 Sokhanvar S, Khoshi A, Hajiaghaei S, Mousavinasab SN, Golmohammadi Z. Association between Apo-lipoprotein-B Levels at admission of patients and short-term morbidity and mortality after myocardial infarction. J Cardiovasc Thorac Res. 2012;4(3):614.
61 Pischon T, Girman CJ, Rifai N, Hotamisligil GS, Rimm EB. Association between dietary factors and plasma adiponectin concentrations in men. Am J Clin Nutr. 2005 Apr;81(4): 780-6.

62 Nakamura Y, Ueshima H, Okuda N, Higashiyama A, Kita Y, Kadowaki T, et al.; INTERLIPID Research Group. Relation of dietary and other lifestyle traits to difference in serum adiponectin concentration of Japanese in Japan and Hawaii: the INTERLIPID Study. Am J Clin Nutr. 2008 Aug;88(2):424-30.

63 Ostrowska L, Fiedorczuk J, Adamska E. Effect of diet and other factors on serum adiponectin concentrations in patients with type 2 diabetes. Rocz Panstw Zakl Hig. 2013;64(1):616.

$64 \mathrm{Wu}$ AH, Yu MC, Stanczyk FZ, Tseng CC, Pike MC. Anthropometric, dietary, and hormonal correlates of serum adiponectin in Asian American women. Nutr Cancer. 2011;63(4): 549-57.
65 Kim YR, Hong SH. Association between the polymorphisms of the vascular endothelial growth factor gene and metabolic syndrome. Biomed Rep. 2015 May;3(3):319-26.

66 Nikzamir A, Esteghamati A, Hammedian AA, Mahmoudi T. The role of vascular endothelial growth factor $+405 \mathrm{G} / \mathrm{C}$ polymorphism and albuminuria in patients with type 2 diabetes mellitus. Mol Biol Rep. 2012 Feb;39(2): 881-6.

67 Steffensen KD, Waldstrøm M, Brandslund I, Jakobsen A. The vascular endothelial growth factor (VEGF) +405 G/C polymorphism and its relationship with recurrent implantation failure in women in an IVF programme with ICSI. Gynecol Oncol. 2010;117(1):109-16.

68 Nachvak SM, Abdollahzad H, Mostafai R. Dietary diversity score and its related factors among employees of Kermanshah university of medical sciences. Clin Nutr Res. 2017;6(4): 247-55. 